\title{
Usos do conceito de eventos privados à luz de proposições pragmatistas $^{1}$
}

\author{
Aécio Borba \\ Emmanuel Zagury Tourinho \\ Universidade Federal do Pará
}

\begin{abstract}
Resumo
O conceito de eventos privados tem sido apontado na literatura da Análise do Comportamento como central para a abordagem de fenômenos relativos à subjetividade, no contexto de uma adesão à instrumentalidade como critério de verdade. Este trabalho discute os usos do conceito de eventos privados a partir de questões levantadas pelo pragmatismo, filosofia com a qual aquele critério de verdade tem sido consistentemente identificado. É examinado em particular o enfoque relacional verbal na análise de conceitos relativos à privacidade, e como esse enfoque se reflete em uma rejeição do mentalismo e do organicismo. O trabalho segue discutindo a importância da comunidade verbal na produção do "mundo privado" individual. Por fim, ressalta-se que alguns autores afastam-se de uma referência funcional/instrumental ao elaborarem o problema da imprecisão de auto-descrições de eventos privados.
\end{abstract}

Palavras-chave: pragmatismo; análise do comportamento; eventos privados; subjetividade.

\begin{abstract}
Uses of the concept of private events from the standpoint of pragmatist assumptions. The concept of private events has been used in behavior-analytic literature as a major topic to the treatment phenomena related to subjectivity, in the context of adopting instrumentality as a criterion of truth. This paper aims to discuss uses of the concept of private events from the standpoint of Pragmatism, a philosophy in which that criterion of truth has been consistently identified. It is particularly examined the focus on verbal relations in the analysis of contents related to privacy, and also how that focus reflects a rejection on mentalism and organicism. The paper continues to discuss the importance of the verbal community in the production of an individual "inside world". In the end, the paper points out that some authors depart from functionalist/instrumentalist reference when working on the problem of imprecision of private events.
\end{abstract}

Keywords: pragmatism; behavior analysis, private events, subjectivity.

$\mathrm{O}$ presente trabalho discute o comportamento verbal de analistas do comportamento ao examinarem fenômenos relativos à subjetividade com o conceito de eventos privados. Mais especificamente, o trabalho focaliza o uso do conceito de eventos privados por analistas do comportamento tendo como referência as proposições pragmatistas de que: (a) a linguagem científica é o produto das práticas de uma comunidade científica, refletindo seus interesses e preocupações; e (b) o discurso cientifico não descreve uma essência da realidade investigada, mas orienta uma interação (produtiva) com a mesma. A decisão de tomar as proposições pragmatistas como referência para a análise dos usos do conceito de eventos privados fundamenta-se na identificação por diversos entre o discurso metacientífico de analistas do comportamento e a concepção de conhecimento e ciência veiculada por autores do pragmatismo (em particular, James \& Rorty-Abib, 1999, 2001b; Lamal, 1983; Lattal \& Laipple, 2003; Leigland, 1999, 2004; Tourinho, 1993, 1994, 1996; Tourinho \& Neno, 2003).

O conceito de eventos privados foi proposto originalmente por Skinner no artigo "The Operational Analysis of Psychologichal Terms" (Skinner, 1945), e tem sido considerado um conceito importante para lidar com temas tradicionais da psicologia, como sentimentos, emoções, cognições etc. Na medida em que o interesse por esses fenômenos está na base da constituição da Psicologia como uma ciência independente, eles constituem também um tema importante para a Análise do Comportamento 
(Tourinho, 1999).

Segundo Skinner (1945), uma parte importante do universo que pode assumir a função de ambiente para um organismo encontra-se no próprio organismo, o que ele mais tarde denominaria de o mundo sob a pele (Skinner, 1953/1965, 1974/1976). De forma semelhante, existem respostas do organismo que não podem ser publicamente observadas (Skinner, 1945). Tais estímulos com origem sob a pele e respostas não observadas publicamente são aquilo que Skinner irá chamar de eventos privados. Ao abordar o problema da subjetividade com esses conceitos, a Análise do Comportamento procura manter uma coerência com seu corpo teórico. Entendidos como estímulos e respostas, eventos privados podem ser tratados como constitutivos de relações comportamentais, assim como estímulos públicos e respostas abertas.

Justifica-se um tratamento diferenciado para estímulos privados e respostas encobertas face à acessibilidade restrita desses eventos, mesmo que, segundo Skinner, não exista qualquer diferença de natureza em relação às suas contrapartes públicas. A introdução do conceito de eventos privados permitiria segundo Skinner (1945, 1974/1976), lidar com os problemas da subjetividade de forma científica.

Conforme mencionado anteriormente, diferentes autores têm apontado que a Análise do Comportamento poderia ser considerada uma ciência cujos critérios de validação do conhecimento são afins aos discutidos em posições pragmatistas (Abib, 2001b; Leigland, 1999, 2004; Tourinho, 1994, 1996; Tourinho \& Neno, 2003). Essa afirmação traz consigo certas implicações para o julgamento da validade dos conceitos da Análise do Comportamento, inclusive para o conceito de eventos privados.

Uma proposição pragmatista sobre a natureza do conhecimento científico é a de que as descrições do mundo são elaboradas por membros de uma comunidade de falantes que compartilham um conjunto de interesses e modos específicos de interação com a realidade. Contemporaneamente, essa noção apóia-se fortemente na obra Investigações Filosóficas (Wittgenstein, 1953/1975).

Para Wittgenstein (1953/1975), a linguagem não deve ser compreendida como um sistema de representação da realidade, uma contrapartida da essência desta. Um conceito constitui simplesmente um modo social arbitrariamente definido de interação com uma parcela da realidade. Seu significado encontra-se nos usos que os membros de uma comunidade fazem dele.

Ainda que não seja propriamente um pensador pragmatista, as reflexões de Wittgenstein sobre a linguagem como modo de ação tiveram importantes repercussões para o pragmatismo, em especial para a obra de Richard Rorty (Rorty, 1998/2005). Rorty (1985/1997c) critica a noção de objetividade do conhecimento científico, apontando que ela está diretamente ligada à tradição da cultura ocidental de buscar uma verdade universal, proposta clara no movimento iluminista. Contudo, tal busca seria fundamentalmente uma reação às verdades teológicas da Igreja e ao ceticismo pós-medieval, quando se buscava um substituto que ocupasse o lugar da crença no divino. O substituto seria justamente uma forma de conhecimento que fosse independente de quaisquer instituições - o conhecimento independente de quem o sustenta. Esse papel foi atribuído ao conhecimento científico.

Ao partir da noção de que qualquer forma de conhecimento é uma descrição do mundo regulada pelas práticas de uma comunidade lingüística, em que o sujeito cognoscente está inserido - noção que acompanha a filosofia de Wittgenstein então é impossível um conhecimento objetivo no sentido acima exposto. A distinção entre objetivo e subjetivo é desnecessária, uma vez que, segundo Rorty (1985/1997c; 1987/1997b), qualquer descrição está limitada pelas práticas lingüísticas da comunidade do falante. A verdade de um enunciado não decorre de uma pretensa concordância com uma realidade última. A verdade é aquilo que é bom, no sentido de que produz uma forma efetiva de operar sobre a realidade.

Rorty (1985/1997c) prefere discutir a validação de um conceito, inclusive conceitos científicos, a partir do que ele chama de solidariedade, em vez da objetividade. A solidariedade está articulada a uma cultura específica e implica que um conhecimento não é verdadeiro ou falso no sentido de representar uma parcela da realidade, mas no sentido de ter sua justificação aceita dentro de uma determinada comunidade de falantes. A aceitação de um conceito ou de uma descrição em uma comunidade de cientistas dependerá, fundamentalmente, do quanto auxilia o cientista para operar de forma efetiva sobre uma parcela da realidade. Esta instrumentalidade define a validade de uma descrição da realidade.

Ao assumir que um conceito científico é uma resposta verbal emitida por uma comunidade científica, em lugar de uma representação da realidade (Skinner, 1957/1992; Tourinho, 1993, 2007), o analista do comportamento abre espaço para lidar com esse conjunto de fenômenos de forma anti-essencialista, aproximando-se de posições pragmatistas. Essa atitude está próxima da noção de objetividade como solidariedade de Rorty (1985/1997c), de acordo com a qual a validade de um conceito está ligada às práticas reforçadoras de uma comunidade científica (Moore, 2000; Tourinho, 2007). O reconhecimento de que respostas verbais científicas são mantidas por uma comunidade verbal, em contraste com a idéia de que representam com maior ou menor precisão realidade, sugere que um compromisso com propostas ou posições representacionistas seria inconsistente com a visão de ciência na qual a Análise do Comportamento se aproxima.

Podemos então questionar: ao abordar a subjetividade, a Análise do Comportamento mantêm a postura antirepresentacionista encontrada na filosofia pragmatista? Afirmações analítico-comportamentais sobre o conhecimento do mundo interno evitam um essencialismo? Ao levantar essas questões, não estamos apontando que a construção da Análise do Comportamento se baseie no pragmatismo. Estamos apontando que questões postas pela filosofia podem contribuir para uma reflexão frutífera sobre os conceitos utilizados por analistas do comportamento para abordar seu objeto de estudo, incluindo aí sua análise sobre emoções e cognições.

$\mathrm{Na}$ Análise do Comportamento, conceitos sobre emoções e cognições podem ser entendidos como respostas verbais, mantidos por contingências de reforço dispostas pela comunidade 
verbal (Skinner, 1945). Eles diriam respeito, então, a formas de interação do homem com o mundo (especialmente, mundo social), e não a entidades com existência independente do sujeito que se comporta e do ambiente onde ele está inserido.

Assumindo que o objeto de estudo da Análise do Comportamento é a relação entre o organismo como um todo e o ambiente (Skinner, 1953/1965, 1974/1976), o analista do comportamento também busca compreender o fenômeno da subjetividade como um fenômeno relacional, de interação entre o homem e o mundo (Tourinho, 2009). Partindo desta posição, discutimos, na seção seguinte, o que significa o enfoque relacional do ponto de vista de algumas de suas implicações, em particular: a rejeição de enfoques não relacionais na abordagem de problemas relativos à privacidade; o mundo privado como função de contingências sócio-verbais; e a questão da imprecisão das auto-descrições: interpretações representacionistas vs. interpretações anti-representacionistas.

\section{Rejeição de enfoques não relacionais na abordagem de problemas relativos à subjetividade}

Ao entender fenômenos psicológicos como relações entre eventos naturais, a Análise do Comportamento rejeita descrições de conceitos sobre emoções e cognições (1) como relações entre eventos de naturezas distintas; e (2) como relações entre eventos pertencentes a outro nível de funcionamento do organismo (ocorrências de partes do organismo, como eventos neurais ou outros processos fisiológicos). Nesse sentido, a análise de fenômenos relacionados à subjetividade, constituise como um anti-mentalismo e um anti-organicismo. Ainda que essa perspectiva prevaleça na literatura, alguns autores (Stemmer, 1992) empregam o conceito de eventos privados como descritivos de ocorrências fisiológicas e produzem análises fisicalistas da subjetividade.

Lidar com os eventos relativos à subjetividade como fenômenos não-relacionais é típico de tradições representacionistas. Nessa visão, como aponta Rorty (1980/1988), a mente funciona como um espelho que reflete a natureza, construindo cópias do mundo. O que o homem conheceria seriam essas cópias.

A posição de que eventos privados têm uma dimensão física é sistematicamente reiterada na literatura analíticocomportamental sobre eventos privados (Creel, 1980; Leigland, 1999; Tourinho, Teixeira, \& Maciel, 2000). Apesar dessa ênfase na existência de uma dimensão física, Abib (2001a) ressalta que, na lógica skinneriana, não há uma escolha pelo físico na dicotomia físico-mental: a própria dicotomia é rejeitada, entendendo que não faz sentido uma divisão dessa natureza. Em uma linha semelhante, Lahren (1976) afirma que termos dualistas "não se relacionam na realidade com questões ontológicas substantivas, mas sim discriminam diferenças em práticas lingüísticas explanatórias de comunidades lingüísticas diferentes ou práticas diversas em uma mesma comunidade. $\mathrm{O}$ dualismo é de natureza lingüística" (p. 93).

A citação aponta uma questão importante: termos mentais dualistas são respostas verbais mantidas por determinadas contingências de reforçamento dispostas por uma comunidade verbal. Antes de avançar para a discussão sobre a importância de contingências sócio-verbais na construção do discurso sobre emoções e cognições como fenômenos internos, contudo, ainda é importante destacar outra postura que o enfoque relacional da Análise do Comportamento rejeita: o organicismo.

O organicismo, a noção de que o comportamento tem como causa iniciadora eventos fisiológicos, tem ganhado força nos últimos anos (Lamal, 1998). Em uma visão organicista, o comportamento se origina no cérebro, e as reações químicas deste órgão explicam desde os fatos mais corriqueiros da vida humana (por exemplo, a suposição de que a paixão é a alta produção de noradrenalina) até transtornos psicológicos (por exemplo, a idéia de que a depressão é uma deficiência de serotonina).

O organicismo, para a literatura analítico-comportamental, mantém o problema de não abordar o comportamento dentro de uma perspectiva relacional (Schnaitter, 1984, 1987; Tourinho et al., 2000). Ao buscar a origem do comportamento no funcionamento de partes do corpo, deixa-se de observar a relação entre esse organismo como um todo e o ambiente.

Afirmar que eventos fisiológicos não podem ser tomados como causa do comportamento não é afirmar que algo não ocorre no interior do organismo quando este se comporta. Vários autores, inclusive Skinner (1974/1976), já afirmaram que pesquisas da área da fisiologia podem contribuir para a ciência do comportamento, na medida em que revelam como funcionam os processos biológicos subjacentes a fenômenos comportamentais. Mas a explicação da fisiologia não se identifica com a da Análise do Comportamento, uma vez que as duas disciplinas estão dando conta de fenômenos distintos, e que essa diferenciação é essencial para o estabelecimento da Psicologia como uma ciência independente (Tourinho, 2006b; Tourinho et al., 2000). Como apontado por Schnaitter (1984), "é a propriedade funcional que faz do operante o que ele é, e não uma propriedade física ou fisiológica" (p. 8). Moore (2001) defende que fenômenos neurofisiológicos, por mais que participem de toda e qualquer atividade comportamental, não podem ser considerados causas do comportamento no sentido em que a Análise do Comportamento entende o conceito de causa:

considere a pressão à barra de um rato. A neurofisiologia certamente participa da atividade motora de pressionar a barra, mas a fisiologia do rato não identifica o estímulo antecedente que exerce controle discriminativo ou o esquema de reforçamento em que uma resposta é reforçada. O mesmo ocorre com fenômenos privados. A neurofisiologia participa do evento comportamental privado, assim como de um evento comportamental público, mas um apelo à fisiologia não explica como o evento comportamental privado desenvolve-se ou como ele vem a exercer controle discriminativo. (Moore, 2001, p. 174)

O raciocínio defendido por autores organicistas é que se o evento privado não é um fenômeno mental, esse fenômeno deve então ser uma condição corporal, ou seja, um evento fisiológico. O que diferencia a posição analítico-comportamental em relação à proposta organicista é que esses fenômenos devem ser compreendidos a partir de sua função. $O$ evento fisiológico assume uma função específica - reforçador, estímulo discriminativo, estímulo aversivo - de acordo com contingências dispostas no ambiente em que o organismo se comporta. Interessa ao analista do comportamento, por exemplo, não se 
o coração acelera diante de certo evento, mas que função essa aceleração assume como parte de uma relação comportamental e, possivelmente, que contingências foram dispostas para que ela assumisse essa função. Tourinho (2006a) aponta que o que pode ser chamado de mundo interno para a Análise do Comportamento "consiste apenas de um aparato anátomofisiológico que é condição para relações comportamentais e que até pode adquirir certas funções de estímulo, mas que não define nem mesmo a resposta do organismo, muito menos as relações comportamentais" (p. 24).

Entretanto, o papel das condições corporais na pesquisa analítico-comportamental ainda é motivo de discussões na literatura. Para alguns autores (Lamal, 1998; Stemmer, 1992) o termo eventos privados reporta-se a fenômenos cujo estudo é atribuição da (neuro)fisiologia, não da Psicologia. Segundo Lamal (1998) e Rachlin (2003), o estudo de eventos privados recai no mesmo problema que a pesquisa organicista: deixa de olhar para a história de reforçamento em busca de variáveis internas, que não podem ser acessadas.

$\mathrm{O}$ anti-mentalismo e anti-organicismo que apresentamos pode ser constatado também em textos pragmatistas, em especial quando a subjetividade é abordada com base nas proposições de Wittgenstein (Day, 1969). Pragmatistas e analistas do comportamento criticam o mentalismo e o organicismo por abordarem conceitos psicológicos como eventos que existem independentemente de uma comunidade verbal. Para autores pragmatistas e analítico-comportamentais, conceitos relativos à privacidade são descrições de certas formas de interação entre o homem e o mundo, e como tal, devem ser compreendidos como práticas verbais que são mantidas em uma comunidade de falantes.

\section{"Mundo privado" como função de contingências sócio-verbais}

Compreender a subjetividade dentro de uma perspectiva tanto analítico-comportamental quanto pragmatista é entendê-la como uma prática lingüística. Para a Análise do Comportamento, conceitos psicológicos são respostas verbais selecionadas por contingências dispostas por uma comunidade verbal que promove a auto-observação e o autocontrole (Tourinho, 2009). Contingências dispostas por uma comunidade verbal podem tornar relevantes estímulos inacessíveis à observação pública direta. Discutiremos aqui que contingências são essas e o controle do comportamento por estímulos privados na sociedade contemporânea.

Segundo Ribes (1982),

na medida em que se concebem declarações verbais que descrevem eventos "privados" ou "subjetivos" como uma forma de interação lingüística que não apenas não corresponde biunivocamente a supostos estados ou eventos, mas que de fato, constituem as formas sociais de construir os referidos eventos - pois os eventos descritos não são mais que relações entre pessoas -, defende-se que a "subjetividade", é dizer a identidade pessoal e as formas de referir-se a ela, são conseqüência das práticas lingüísticas da sociedade. (p. 25)

Como apontado por Ribes (1982), o conceito de subjetividade é uma forma de descrever determinadas relações entre o homem e o mundo, em especial com outros homens. Descrever um fenômeno como físico ou mental, subjetivo ou objetivo, público ou privado, é descrever diferentes formas de relação, não diferentes naturezas desses fenômenos. Os problemas relativos à subjetividade são problemas sobre que contingências em operação mantêm estas descrições (Day, 1969). Portanto, esses problemas são de natureza verbal.

Em uma cultura marcada pelo individualismo, os fenômenos emocionais e cognitivos começam a ser considerados no senso comum como entidades ou eventos que ocorrem no interior do organismo, sejam em uma mente imaterial ou no cérebro. Segundo Moore (1975), "é um uso cultural que desmerecidamente eleva comportamento concreto a um misterioso processo mental, e desse modo inibe sua análise" (p. 129).

Dizer que os fenômenos relativos à subjetividade são constituídos a partir de contingências verbais implica que, ao buscar as contingências que controlam verbalizações a respeito do mundo interno, sempre serão encontradas contingências públicas.

A impossibilidade de uma linguagem puramente privada é argumentada na análise de Wittgenstein (1953/1975), e foi também elaborada por Skinner (1945). A base desse argumento é a idéia de que toda resposta verbal tem origem social. Uma palavra não é a descrição de uma essência, mas uma resposta verbal que desempenha uma função em uma comunidade verbal. Essa função é semelhante para os membros dessa comunidade, por convenção. Não existe qualquer propriedade da palavra que determine seu uso. As convenções que definem a função de uma verbalização são arbitrárias, e não existe uma correspondência formal entre uma determinada parcela da realidade e a palavra. Se qualquer resposta verbal é emitida em acordo com critérios convencionados, não há como uma palavra descrever algo com o que apenas um único sujeito possa entrar em contato. Não é possível afirmar que existe uma parcela da realidade que adquire sentido independente da interação entre sujeito e comunidade verbal. O mundo interno (ou estes estímulos privados) adquire sentido (ou função) a partir desta interação.

Desse modo, alguns autores apontam que mesmo ao estar se referindo a eventos relativos à subjetividade, o sujeito emite respostas verbais sob controle de eventos públicos, partilhados pela comunidade verbal (Deitz \& Arrington, 1984; Lahren, 1976; Morris, 1985; Ribes, 1982; Tourinho, 2006a, 2006b, 2009). Como apontado por Tourinho (2006b), "respostas verbais descritivas de eventos privados são adquiridas sob controle de um conjunto de estímulos que incluem estímulos públicos (esses tornando possível a ação reforçadora da comunidade verbal)" (p. 16).

A partir da compreensão de que o mundo interno do indivíduo é constituído em interação com contingências sócioverbais dispostas pela cultura em que ele está inserido, mantêmse uma coerência entre um tratamento de temas relativos à subjetividade e o sistema explicativo analítico-comportamental. É possível assim abordar os termos chamados mentais dentro de uma perspectiva relacional e monista.

É também papel da comunidade verbal a disposição de contingências que tornam possíveis as descrições do próprio 
comportamento (Skinner, 1974/1976; Tourinho, 2006b, 2009). Segundo Gongorra e Abib (2001), Skinner

entende que, sem a participação de um grupo social que fale uma mesma língua e compartilhe alguma cultura comum, ao qual ele denominou comunidade verbal, não é possível conhecer o mundo privado. Isto porque ele pressupõe que, de início, o mundo privado de cada um, tal como o ambiente, não é diferenciado. (p. 15-16)

O autoconhecimento é possível apenas quando contingências verbais dispostas pela comunidade selecionam verbalizações descritivas do próprio comportamento. É importante lembrar, contudo, que o comportamento humano é multideterminado, sendo selecionado em variados níveis e dentro de um processo histórico que se estende por toda a vida do sujeito (Skinner, 1981/1988). Com isso, torna-se difícil (ou impossível) descrever todas as variáveis das quais o comportamento é função. É então que, novamente, a cultura age favorecendo a descrição do próprio comportamento sob controle de ocorrências internas ao sujeito.

Em culturas ocidentais modernas, contingências sociais não favorecem a discriminação de todas as fontes de controle de repertórios auto-descritivos. Elas favorecem mais freqüentemente a discriminação do que ocorre no corpo do que a discriminação de relações comportamentais. É a exposição a contingências verbais que dá origem ao ambiente privado sobre o qual falamos e que faz alguns eventos fisiológicos adquirirem um controle discriminativo parcial de respostas verbais. (Tourinho, 2006b, p. 17)

Respostas sob controle de estímulos privados, apesar de selecionadas a partir de práticas individualistas, desempenham um importante papel na relação entre as pessoas na cultura ocidental contemporânea. Reconhecer os eventos que levam a essa importância é essencial para a compreensão da manutenção de relatos verbais sobre eventos privados.

Alguns aspectos de tradições culturais contemporâneas têm sido apontados como mantenedores de verbalizações sobre eventos privados como causas do comportamento. Hayes e Wilson (1994) consideram importante o impacto de considerar literalmente o significado de referências a sentimentos, emoções e cognições como coisas, como em tenho muito amor dentro de mim. Além disso, é comum ouvir a afirmação do senso comum, de que ser guiado pelas emoções e pensamentos é o único meio adequado para levar a vida, uma noção bastante presente desde o movimento romântico de valorização da interioridade. A cultura ocidental, assim, reforça a auto-observação do comportamento, a partir de máximas como conhece a ti mesmo, ou pessoas felizes são aquelas que agem com o coração.

No senso comum explicações baseadas em emoções e cognições são consideradas suficientes pela comunidade verbal para explicar o próprio comportamento. Se uma pessoa diz que enviou flores para sua mãe porque a ama, isso é considerado para a grande maioria das pessoas como uma explicação válida. E esta resposta seria mais provavelmente reforçada socialmente do que dizer que o presente foi dado porque ela fez um almoço especial semana passada (descrevendo as contingências de controle da resposta naquele momento). Explicações baseadas em sentimentos, emoções e pensamentos são econômicas, permitindo que as pessoas no dia a dia tenham acesso a informações que as permitem lidar de forma adequada com outras pessoas.

$\mathrm{Na}$ mesma linha de Hayes e Wilson (1994), Anderson, Hawkins e Scotti (1997) apontam razões que criam a predileção por explicações baseadas em eventos privados na linguagem cotidiana. Para os autores, emoções e cognições são consideradas fenômenos internos pelo discurso cotidiano. À medida que o sujeito passa a responder verbalmente de um determinado modo a aspectos corporais, tais eventos começam a fazer parte de redes de relações entre estímulos e podem adquirir indiretamente outras funções. Por exemplo, em uma situação aversiva, uma pessoa pode dizer que está com medo, e práticas da comunidade verbal dizem que o medo é aquilo que é sentido pelo sujeito como estímulos interoceptivos ou proprioceptivos. Em outras situações, aquela sensação corporal pode controlar a resposta do sujeito de dizer estou com medo.

Na medida em que condições corporais vão sendo associadas a explicações do comportamento, elas passam a assumir uma função importante na linguagem cotidiana, comunicando a outras pessoas determinados padrões de comportamento do sujeito. Ao afirmar que tenho preguiça, é pouco provável que eu vá sair de casa, por exemplo. Segundo Wilson e Hayes (2000), "explicações emocionais e cognitivas são formas de discurso que servem como predições para eventos futuros, e podem alterar o ambiente social através da persuasão de outros ou por um apelo a razões convencionais de explicações do comportamento" (p. 30). Morris (1985) ressalta que falar de forma mentalista em uma cultura internalista, para os efeitos das relações cotidianas, é produtivo. É quando queremos uma linguagem científica que termos mentais passam a ser pouco funcionais.

O papel da comunidade verbal é essencial para compreender os conceitos cognitivos e emocionais em uma perspectiva relacional, como foi discutido nessa seção. Salientar essa importância é fundamental para uma abordagem pragmatista da subjetividade. Tal perspectiva concorre na Análise do Comportamento com perspectivas e tratamentos sobre emoções e cognições que podem ser aproximados do representacionismo. A próxima seção desenvolve essa questão.

\section{A questão da "imprecisão" das auto-descrições}

Em uma visão pragmatista, conceitos empregados na referência a fenômenos emocionais e cognitivos não descrevem essências internas, assim como conceitos empregados na referência a fenômenos atmosféricos não descrevem propriedades essenciais de uma natureza física da Terra. Ao descrever as cognições e emoções, o sujeito continua sob controle de contingências dispostas por uma comunidade verbal. Essa proposição aproxima Análise do Comportamento e Pragmatismo. Alguns analistas do comportamento, porém, partem da idéia de que respostas autodescritivas de emoções podem vir a ficar parcialmente sob controle de ocorrências corporais e daí derivam a sugestão de que a precisão (ou validade) dessas autodescrições é uma questão de correspondência entre a resposta verbal e o evento corporal. Nesse momento, afastam-se de uma concepção 
funcional/pragmatista da linguagem e da ciência.

A relação entre eventos corporais (geralmente fisiológicos) e respostas autodescritivas de emoções é examinada por vários autores na Análise do Comportamento. Para alguns (Creel, 1980; Gongorra \& Abib, 2001; Lamal, 1998; Moore, 1980, 2001; Skinner, 1945), uma vez que se compreendam conceitos emocionais e cognitivos como respostas verbais, deve-se reconhecer que não há como os membros de uma comunidade terem certeza de que eventos específicos estão assumindo o controle do comportamento verbal.

[Ensinar uma pessoa a discriminar a cor vermelha] pode ser feito facilmente se tanto a comunidade quanto o indivíduo tiverem acesso a estímulos vermelhos. Não pode acontecer se tanto o indivíduo como a comunidade forem cegos para cores. Este último caso se assemelha àquele no qual uma resposta verbal se baseia em um evento privado, no qual, por definição, é impossível o comum acesso de ambas as partes. Como a comunidade apresenta ou mantém sob o controle de estimulação apropriada o reforço para ter uma resposta como "Meu dente dói"? Poderia estabelecer facilmente a resposta "Meu dente está quebrado" porque tanto o indivíduo quanto a comunidade têm acesso ao estímulo para "quebrado", mas a comunidade não tem um acesso comparável para estímulos que controlem “dores". (Skinner, 1953/1965, p.259)

Nos exemplos citados, descrições que se reportem a fenômenos privados não podem, portanto, ser consideradas precisas como as que se referem a eventos públicos, em que tanto falante quanto ouvinte têm acesso direto ao evento que será nomeado. O ouvinte precisaria basear-se não no relato de fenômenos privados, mas em acompanhamentos públicos do fenômeno privado (um ferimento, por exemplo, seria um acompanhamento público válido para auto-descrições de dor), ou comportamentos colaterais (encolher-se quando a região dolorida é tocada). Segundo Skinner (1945), "auto-descrições de fenômenos privados por outros podem não ser confiáveis. Falantes podem estar influenciados por motivações conflituosas e conseqüentemente se engajar em distorções ficcionais" (p. 275). A posição de Moore (2001) concorda com Skinner (1945), ao afirmar que "existem limitações no estabelecimento da precisão de discriminações. Presumivelmente, ouvintes buscam evidências adicionais do tipo identificado anteriormente, como acompanhamentos públicos ou respostas colaterais, antes de aceitar a descrição do falante de dor" (Moore, 2001, p. 173).

É importante demarcar, entretanto, que a concepção de que as descrições de eventos privados são menos confiáveis que as descrições de eventos públicos apresentam de forma implícita a compreensão de que fenômenos internos possuem uma essência que pode ser descrita de forma mais ou menos precisa. Essa lógica mantém um olhar para a estrutura dos fenômenos privados, focando-se em propriedades próprias a eles.

Outro conjunto de autores, contudo, aponta que os conceitos cognitivos e emocionais dizem respeito a uma forma de referir-se a um determinado conjunto de relações comportamentais estabelecidas em uma dada comunidade verbal (Leigland, 1999, 2003; Ribes, 1982; Schnaitter, 1978; Tourinho, 1994, 2006b). Esses fenômenos têm uma dimensão pública, mesmo que estimulações de acessibilidade restrita estejam circunstancialmente controlando tais verbalizações, como apontado anteriormente na discussão da impossibilidade de uma linguagem capaz de descrever eventos inteiramente privados (Skinner, 1945; Tourinho, 2009; Wittgenstein, 1953/1975). Esses autores veiculam outra noção sobre a validade de verbalizações auto-descritivas.

Segundo Schnaitter (1978), não são apenas descrições de eventos privados que podem ter seu controle considerado impreciso ou confuso. Quando uma pessoa tateia eventos públicos, ela também pode emitir respostas que não seriam confiáveis por outras pessoas. Certa pessoa pode não ser capaz de tatear de forma adequada (para certos padrões) uma determinada cor, caso ela não tenha sido exposta a contingências verbais adequadas para diferenciar as cores rosa, lavanda e salmão, por exemplo. Os relatos verbais desta pessoa a respeito de cores semelhantes poderiam ser reconhecidos como tendo tão pouca credibilidade quando relatos verbais sobre eventos privados.

Se a subjetividade tem a ver com certas descrições feitas pela comunidade verbal (Leigland, 1999, 2003; Ribes, 1982; Tourinho, 2006b), os termos cognitivos e emocionais constituem descrições de determinadas formas de interação entre o homem e seu ambiente, sendo emitidos em circunstâncias diferentes daquelas que controlam respostas que não dizem respeito à subjetividade. Segundo Ribes (1982):

a subjetividade, privacidade e/ou internalidade dos eventos psicológicos não têm relação com seu estatuto de existência como eventos físicos ou eventos "mentais", e sim constitui um problema relacionado com os níveis de descrição que uma comunidade lingüística estabelece para referir-se a formas particulares de interação de uma pessoa com outra ou consigo mesma. (p. 19)

Não há, portanto, uma distinção de essências entre o que é acessível e não acessível, aquilo que pode ser nomeado de forma adequada ou aquilo que a acessibilidade restrita dificulta à comunidade descrever de forma apropriada. $\mathrm{O}$ que podemos apontar é uma diferença na forma como essas atividades do sujeito são compreendidas pela comunidade verbal.

\section{Considerações finais}

A postura relacional no tratamento da subjetividade, incluindo aqui seu anti-mentalismo e a compreensão funcional da linguagem, constitui um dos pontos fundamentais de aproximação entre Análise do Comportamento e posições pragmatistas. Se compreendermos um conceito como uma resposta verbal emitida por uma comunidade científica, uma visão não-representacionista do conceito de eventos privados é essencial para manter a coerência do conceito com o sistema explicativo analítico-comportamental. Ao compreender o conceito de eventos privados como uma resposta verbal emitida por analistas do comportamento quando estes abordam os problemas relativos à subjetividade, é importante reconhecer que o conceito não descreve uma essência desses eventos. Ele constitui uma forma de sistematizar o conhecimento sobre essas questões e orientar a ação do pesquisador ou profissional 
sobre elas (Rorty, 1988/1997a, 1987/1997b). As dimensões lingüísticas do conceito de eventos privados refletem esse nãoessencialismo e como analistas do comportamento procuram discutir criticamente abordagens representacionistas do problema da subjetividade.

Woofolk (1983) aponta que pragmatistas e behavioristas radicais possuem os mesmos inimigos, que são as perspectivas mentalistas da subjetividade, que se assemelham a abordagens representacionistas. Uma das soluções encontradas tanto por analistas do comportamento quanto por pragmatistas para lidar com conceitos emocionais e cognitivos sem recorrer ao mentalismo está na abordagem relacional dos fenômenos. Encontramos na literatura analítico-comportamental analistas do comportamento criticam abordagens mentalistas e organicistas, que tendem a identificar emoções e cognições como ocorrências no ou do indivíduo. Tal perspectiva traria uma inconsistência com o objeto de estudo da Análise do Comportamento, que entende o comportamento (e, portanto, emoções e cognições) como relações entre organismo e ambiente.

A abordagem analítico-comportamental de emoções, sentimentos e cognições também se aproximam do pragmatismo ao atribuir grande importância ao tratamento da subjetividade como fenômeno verbal. Essa visão pode ser considerada nãoessencialista e não representacionista.

É importante ressaltar, por último, que o antirepresentacionismo não é a única aproximação possível entre pragmatismo e Análise do Comportamento. A literatura que aproxima as duas disciplinas com freqüência o faz apontando que ambos assumem critérios instrumentais de validação do conhecimento (Abib, 1999; Leigland, 1999; Tourinho, 1993, 1994, 1996; Tourinho \& Neno, 2003). Não foi nosso objetivo aqui desenvolver tal análise, mas salientamos sua importância para uma complementação da discussão da relação entre Análise do Comportamento e Pragmatismo.

\section{Referências}

Abib, J. A. D. (1999). Behaviorismo radical e discurso pós-moderno. Psicologia: Teoria e Pesquisa, 15(3), 237-247.

Abib, J. A. D. (2001a). Arqueologia do behaviorismo radical e o conceito de mente. In H. J. Guilhardi, M. B. B. P. Madi, P. P. Queiroz \& M. C. Scoz (Orgs.), Sobre comportamento e cognição: expondo a variabilidade (Vol. 7, pp. 20-35). Santo André, SP: ESETec.

Abib, J.A. D. (2001b). Behaviorismo radical como pragmatismo na epistemologia. In H. J. Guilhardi, M. B. B. P. Madi, P. P. Queiroz \& M. C. Scoz (Orgs.), Sobre comportamento e cognição: expondo a variabilidade (Vol. 8, pp. 158-161). Santo André, SP: ESETec.

Anderson, C. M., Hawkins, R. P., \& Scotti, J. R. (1997). Private events in behavior analysis: Conceptual basis and clinical relevance. Behavior Therapy, 28(11), 157-179.

Creel, R. (1980). Radical epiphenomenalism: B. F. Skinner's account of private events. Behaviorism, 8, 31-53.

Day, W. F. (1969). On certain similarities between the Philosophical Investigations of Ludwig Wittgenstein and the operationism of B. F. Skinner. Journal of the Experimental Analysis of Behavior, 12(3), 489-506.

Deitz, S. M., \& Arrington, R. L (1984). Wittgenstein's language-games and the call to cognition. Behaviorism, 12(2), 1-14.

Gongorra, M. A. N., \& Abib, J. A. D. (2001). Questões referentes à causalidade e eventos privados no behaviorismo radical. Revista Brasileira de Terapia
Comportamental e Cognitiva, 3(1), 9-24.

Hayes. S. C., \& Wilson, K. G. (1994). Acceptance and commitment therapy: altering the verbal support for experiential avoidance. The Behavior Analyst, 17(2), 289-303.

Lahren, B. (1976). Commentary on Margolis' paper “mental states”. Behaviorism, 4, 77-95.

Lamal, P. A. (1983). A cogent critique of epistemology leaves radical behaviorism unscathed. Behaviorism, 11, 103-109.

Lamal, P. A. (1998). Advancing backwards. Journal of Applied Behavior Analysis, 31(4), 705-706.

Lattal, K. A., \& Laipple, J. S. (2003). Pragmatism and behavior analysis. In K. A. Lattal \& P. N. Chase (Orgs.), Behavior theory and philosophy (pp. 41-61). Nova York: Kluwer Academic/Plenum.

Leigland, S. (1999). Pragmatism, science, and society: a review of Richard Rorty's Objectivity, Relativism, and Truth: philosophical papers (vol. 1). Journal of the Experimental Analysis of Behavior, 71(3), 483-500.

Leigland, S. (2003). Private events and the language of the mental: comments on Moore. Behavior and Philosophy, 31, 159-164.

Leigland, S. (2004). Pragmatism and radical behaviorism: comments on Malone (2001). Behavior and Philosophy, 32, 305-312.

Moore, J. (1975). On the principle of operationism in a science of behavior Behaviorism, 3(2), 120-138.

Moore, J. (1980). On behaviorism and private events. The Psychological Record, $30,459-475$.

Moore, J. (2000). Varieties of scientific explanation. The Behavior Analyst, 23(2), 173-190.

Moore, J. (2001). On psychological terms that appeal to the mental. Behavior and Philosophy, 29, 167-186.

Morris, E. K. (1985). "Wittgenstein's language-games and the call to cognition": comments on Deitz and Arrington. Behaviorism, 13(2), 137-146.

Rachlin, H. (2003). Privacy. In K. A. Lattal \& P. N. Chase (Orgs.), Behavior theory and philosophy (pp. 187-201). Nova York: Kluwer Academic/Plenum.

Ribes, E. (1982). Los eventos privados: ¿Un problema para la teoría de la conducta? Revista Mexicana de Análisis de la Conducta, 8(1), 11-29.

Rorty, R. (1988). A filosofia e o espelho da natureza (J. Pires, Trad.). Lisboa: Dom Quixote. (Publicado originalmente em 1980)

Rorty, R. (1997a). A ciência natural é um gênero natural? In R. Rorty (Org.), Objetivismo, relativismo e verdade (M. A. Casanova, Trad.; pp. 69-90). Rio de Janeiro: Relume-Dumará. (Publicado originalmente em 1988)

Rorty, R. (1997b). Ciência enquanto solidariedade. In R. Rorty (Org.), Objetivismo, relativismo e verdade (M. A. Casanova, Trad.; pp. 55-68). Rio de Janeiro: Relume-Dumará. (Publicado originalmente em 1987)

Rorty, R. (1997c). Solidariedade ou objetividade? In R. Rorty (Org.), Objetivismo, relativismo e verdade (M. A. Casanova, Trad.; pp. 37-54). Rio de Janeiro: Relume-Dumará. (Publicado originalmente em 1985)

Rorty, R. (2005). Introdução. In R. Rorty (Org.), Verdade e progresso (D. R. Sales, Trad.; pp. 7-25). Barueri, SP: Manole. (Publicado originalmente em 1998)

Schnaitter, R. (1978). Private causes. Behaviorism, 6(1), 1-12.

Schnaitter, R. (1984). Skinner on the "mental" and the "physical". Behaviorism, 12(1), 1-14.

Schnaitter, R. (1987). Behaviorism is not cognitive and cognitivism is not behavioral. Behaviorism, 15, 1-11.

Skinner, B. F. (1945). The operational analysis of psychological terms Psychological Review, 52, 270-277/291-294.

Skinner, B. F. (1965). Science and human behavior. Nova York: The Free Press. (Publicado originalmente em 1953)

Skinner, B. F. (1976). About behaviorism. Nova York: Vintage Books. (Publicado originalmente em 1974)

Skinner, B. F. (1988). Selection by consequences. In A. C. Catania \& S. Harnad (Orgs.), The selection of behavior: the operant behaviorism of B.F. Skinner: comments and consequences (pp. 11-20). Nova York: Cambridge University Press. (Publicado originalmente em 1981) 
Skinner, B. F. (1992). Verbal behavior. Cambridge, Massachussets: B. F. Skinner Foundation. (Publicado originalmente em 1957)

Stemmer, N. (1992). Skinner and a solution to the problem of inner events. The Behavior Analyst, 15(2), 115-128.

Tourinho, E. Z. (1993). A noção pragmatista de conhecimento e a noção skinneriana de conhecimento de si mesmo. Acta Comportmentalia, 2(2), 219-232.

Tourinho, E. Z. (1994). Behaviorismo radical, representacionismo e pragmatismo: Uma discussão epistemológica do pensamento de B. F. Skinner. Tese de Doutorado, Instituto de Psicologia, Universidade de São Paulo, São Paulo.

Tourinho, E. Z. (1996). Behaviorismo radical, representacionismo e pragmatismo. Temas em Psicologia, 4(2), 41-56.

Tourinho, E. Z. (1999). Eventos privados: o que, como e por que estudar. In R R. Kerbauy \& R. C. Wielenska (Orgs.), Sobre comportamento e cognição: psicologia comportamental e cognitiva: da reflexão teórica à diversidade na aplicação (pp. 13-25). Santo André, SP: ESETec.

Tourinho, E. Z. (2006a). Mundo interno e autocontrole. Revista Brasileira de Análise do Comportamento, 2(1), 21-36.
Tourinho, E. Z. (2006b). Private stimuli, covert responses, and private events: Conceptual remarks. The Behavior Analyst, 29(1), 13-31.

Tourinho, E. Z. (2007). Conceitos cientificos e "eventos privados" como resposta verbal. Interação em Psicologia, 11, 1-9.

Tourinho, E. Z. (2009). Subjetividade e relações comportamentais. São Paulo: Paradigma.

Tourinho, E. Z., \& Neno, S. (2003). Effectiveness as truth criterion in behavior analysis. Behavior and Philosophy, 31(1), 63-81.

Tourinho, E. Z., Teixeira, E. R., \& Maciel, J. M. (2000). Fronteiras entre análise do comportamento e fisiologia: Skinner e a temática dos eventos privados. Psicologia: Reflexão e Crítica, 13(3), 425-434.

Wilson, K. G., \& Hayes, S. C. (2000). Why it is crucial to understand thinking and feeling: an analysis and application to drug abuse. The Behavior Analyst, 23(1), 25-43.

Wittgenstein, L. (1975). Investigações filosóficas. São Paulo: Abril Cultural. (Publicado originalmente em 1953)

Woofolk, R. L. (1983). Behaviorism, Rorty and the end of epistemology. Behaviorism, 11, 111-113

1. Este artigo reproduz partes da Dissertação de Mestrado apresentada pelo primeiro autor ao Programa de Pós-Graduação em Teoria e Pesquisa do Comportamento, Universidade Federal do Pará, e orientada pelo segundo autor. Trabalho parcialmente financiado pela Coordenadoria de Aperfeiçoamento de Pessoal de Nível Superior, CAPES (Bolsa de Mestrado), e Conselho Nacional de Desenvolvimento Científico e Tecnológico, CNPq (Processos 304116/2007-6 e 480727/2007-4).

Aécio Borba, mestre em Teoria e Pesquisa do Comportamento, pela Universidade Federal do Pará (UFPA), é doutorando do Programa de Pós-Graduação em Teoria e Pesquisa do Comportamento, na mesma universidade. Endereço para correspondência: Núcleo de Teoria e Pesquisa do Comportamento, Programa de Pós-Graduação em Teoria e Pesquisa de Comportamento, Universidade Federal do Pará. Rua Augusto Corrêa, 1, Guamá, Belém, PA, 66075-110. Telefone/Fax: +55 (91) 3201-7662 / (91) 3201-8476. E-mail: aecioborba@gmail.com

Emmanuel Zagury Tourinho, doutor em Psicologia Experimental pela Universidade de São Paulo (USP), é professor titular do Núcleo de Teoria e Pesquisa do Comportamento da Universidade Federal do Pará (UFPA). E-mail: eztourinho@gmail.com 